\title{
Effects of particulate matter on hospital admissions for respiratory diseases: an ecological study based on 12.5 years of time series data in Shanghai
}

\author{
Wenjia Peng ${ }^{1}$, Hao Li ${ }^{1}$, Li Peng ${ }^{2}$, Ying Wang ${ }^{3,5^{*}}$ and Weibing Wang ${ }^{1,2,4^{*}}$ (])
}

\begin{abstract}
Background: Previous epidemiological studies on the association between short-term exposure to particulate matter (PM) with hospital admission in major cities in China were limited to shorter study periods or a single hospital. The aim of this ecological study based on a 12.5-year time series was to investigate the association of short-term exposure to PM with aerodynamic diameter $\leq 2.5 \mu \mathrm{m}\left(\mathrm{PM}_{2.5}\right)$ and aerodynamic diameter $\leq 10 \mu \mathrm{m}\left(\mathrm{PM}_{10}\right)$ with hospital admissions for respiratory diseases.

Methods: Daily hospital admissions data were from the Shanghai Medical Insurance System for the period January 1, 2008 to July 31, 2020. We estimated the percentage change with its $95 \%$ confidence interval (Cl) for each $10 \mu \mathrm{g} /$ $\mathrm{m}^{3}$ increase in the level of $\mathrm{PM}_{2.5}$ and $\mathrm{PM}_{10}$ after adjustment for calendar time, day of the week, public holidays, and meteorological factors applying a generalized additive model with a quasi-Poisson distribution.

Results: There were 1,960,361 hospital admissions for respiratory diseases in Shanghai during the study period. A $10 \mathrm{\mu g} / \mathrm{m}^{3}$ increase in the level of each class of PM was associated with increased total respiratory diseases when the lag time was 0 day (PM $\left.2.5: 0.755 \% ; 95 \% \mathrm{Cl}: 0.422,1.089 \% ; \mathrm{PM}_{10}: 0.250 \% ; 95 \% \mathrm{Cl}: 0.042,0.459 \%\right)$. The $\mathrm{PM}_{2.5}$ and $\mathrm{PM}_{10}$ levels also had positive associations with admissions for COPD, asthma, and pneumonia. Stratified analyses demonstrated stronger effects in patients more than 45 years old and during the cold season. Total respiratory diseases increased linearly with PM concentration from 0 to $100 \mu \mathrm{g} / \mathrm{m}^{3}$, and increased more slowly at higher PM concentrations.
\end{abstract}

Conclusions: This time-series study suggests that short-term exposure to PM increased the risk for hospital admission for respiratory diseases, even at low concentrations. These findings suggest that reducing atmospheric PM concentrations may reduce hospital admissions for respiratory diseases.

Keywords: Particulate matter, Respiratory diseases, Hospital admission, Time series

*Correspondence: wangying1013@fudan.edu.cn; wwb@fudan.edu.cn

${ }^{4}$ Department of Social Medicine, School of Public Health, Fudan

University, Shanghai 200032, China

${ }^{5}$ IRDR-ICoE on Risk Interconnectivity and Governance on Weather/

Climate Extremes Impact and Public Health, Fudan University, Shanghai 200032, China

Full list of author information is available at the end of the article

\section{Background}

Respiratory diseases, including chronic obstructive pulmonary disease (COPD), asthma, interstitial lung disease, and pulmonary sarcoidosis, are major public health problems that impose a huge disease burden on society [1]. The disability-adjusted life years (DALYs) of respiratory diseases increased from 97.2 to 112.3 million a year from original author(s) and the source, provide a link to the Creative Commons licence, and indicate if changes were made. The images or other third party material in this article are included in the article's Creative Commons licence, unless indicated otherwise in a credit line to the material. If material is not included in the article's Creative Commons licence and your intended use is not permitted by statutory regulation or exceeds the permitted use, you will need to obtain permission directly from the copyright holder. To view a copy of this licence, visit http://creativecommons.org/licenses/by/4.0/. The Creative Commons Public Domain Dedication waiver (http://creativeco mmons.org/publicdomain/zero/1.0/) applies to the data made available in this article, unless otherwise stated in a credit line to the data. 
1990 to 2017 [2]. There are two well-known risk factors associated with respiratory diseases: behavioral factors (e.g. smoking) and environmental factors (e.g. air pollution) [2].

China is now faced with severe air pollution due to rapid urbanization and industrialization, especially in the more populous areas. According to the global burden of disease study 2017 [3], 1.24 million deaths were attributable to air pollution exposure, and air pollution resulted in 40.0 and $35.6 \%$ of DALYs for COPD and lower respiratory infections in China, respectively. To cope with the severe air pollution problem, the Chinese government has implemented several policies and regulations to improve the air quality and issued the Chinese National Ambient Air Quality Standard (GB3095-2012) in 2012, which limited the annual and 24-h mean concentrations of the major pollutants.

The most common pollutants are particulate matter (PM) with an aerodynamic diameter less than or equal to $2.5 \mu \mathrm{m}\left(\mathrm{PM}_{2.5}\right)$ and with an aerodynamic diameter less than or equal to $10 \mu \mathrm{m}\left(\mathrm{PM}_{10}\right)$. Longtime exposure to $\mathrm{PM}$ can cause multiple health problems that reduce human longevity [4]. Although numerous ecological studies have investigated the association between PM and outpatient or inpatient admissions of respiratory diseases, most of them were usually conducted for a relatively shorter study period [5-8] or a single hospital $[7,9]$ with a limited number of outcomes. Moreover, some studies [5, 8, 10] on the association of PM with respiratory diseases have produced inconsistent results.

Shanghai is the most populous megacity with a permanent population of 24.8 million in the seventh national census. It is also one of the heaviest polluted cities in China. The present study used time-series data for 12.5 years from all the medical insurance designated hospitals from Shanghai Healthcare Security Database for Urban Employees and Urban and Rural Residents. The database covers more than $95 \%$ of the adult population in Shanghai according to statistics released by the National Healthcare Security Administration, resulting in having a large number of hospitalizations and therefore providing good statistical power to examine the respiratory disease subcategories. We have investigated the association of short-term exposure to $\mathrm{PM}_{2.5}$ and $\mathrm{PM}_{10}$ with total respiratory diseases and subcategories (COPD, asthma, and pneumonia) in Shanghai.

\section{Methods}

\section{Respiratory disease data}

Daily hospital admissions data were from the Shanghai Medical Insurance System for the period January 1, 2008 to July 31,2020 . The clinical diagnostic criteria for respiratory diseases were from the International Classification of Diseases, 10th Revision as J00 to J99. This included COPD (J40-J44), asthma (J45), and pneumonia (J12-J18). Patients' basic information included gender and age (<45years, 45-64years, 65-74years, and $\geq 75$ years). Prior to data collection, this study was approved by the Ethics Committee of the School of Public Health, Fudan University.

\section{Air pollutants and meteorological data}

We collected six of the most common air pollutants from the Shanghai Municipal Bureau of Ecological Environment (https://sthj.sh.gov.cn/), namely $\mathrm{PM}_{2.5}$, $\mathrm{PM}_{10}$, nitrogen dioxide $\left(\mathrm{NO}_{2}\right)$, sulfur dioxide $\left(\mathrm{SO}_{2}\right)$, ozone $\left(\mathrm{O}_{3}\right)$, and carbon monoxide $(\mathrm{CO})$. Of these, the daily concentrations of $\mathrm{PM}_{10}, \mathrm{NO}_{2}$, and $\mathrm{SO}_{2}$ were available from January 1, 2008 to July 31, 2020. While, daily $\mathrm{PM}_{2.5}, \mathrm{O}_{3}$, and $\mathrm{CO}$ concentrations were only available after the establishment of the ground monitoring network after January 1, 2013.There are 19 environmental monitoring stations in Shanghai (Fig. 1). The daily concentration of air pollutants was simply an arithmetic mean measure across all the monitoring stations, as in most time-series studies. Meteorological data (mean temperature and relative humidity) in Shanghai were from the National Meteorological Information Center (http://data.cma.cn/).

\section{Statistical analysis}

A generalized additive model (GAM) [11] with a quasiPoisson distribution was adopted to analyze the impact of $\mathrm{PM}_{2.5}$ and $\mathrm{PM}_{10}$ on daily hospital admissions of respiratory diseases. The effect of different time lags was examined including six single-day lags: $(i)$ lag 0 , the present day; (ii) lag 1, the previous day; (iii) lag 2, the day before lag 1; (iv) lag 3, the day before lag 2; (v) lag 4, the day before lag $3 ;(v i) \operatorname{lag} 5$, the day before lag 4 , and three moving average exposure lags: $(i)$ lag 01 , the 2-day moving average of the present and previous day; (ii) lag 02, the 3-day moving average of the present and previous 2 days; (iii) lag 03, the 4-day moving average of the present and previous 3 days.

Based on previous studies $[12,13]$, the following covariates were used: $(i)$ a natural spline function of calendar time with 7 degrees of freedom per year (to exclude unmeasured time trends); (ii) a natural spline function with 6 degrees of freedom for present-day mean temperature and 3 degrees of freedom for present-day relative humidity (to control for the nonlinear confounding effects of weather conditions); and (iii) indicator variables for day of the week (DOW) and public holidays (PH). Therefore, the main model was: 


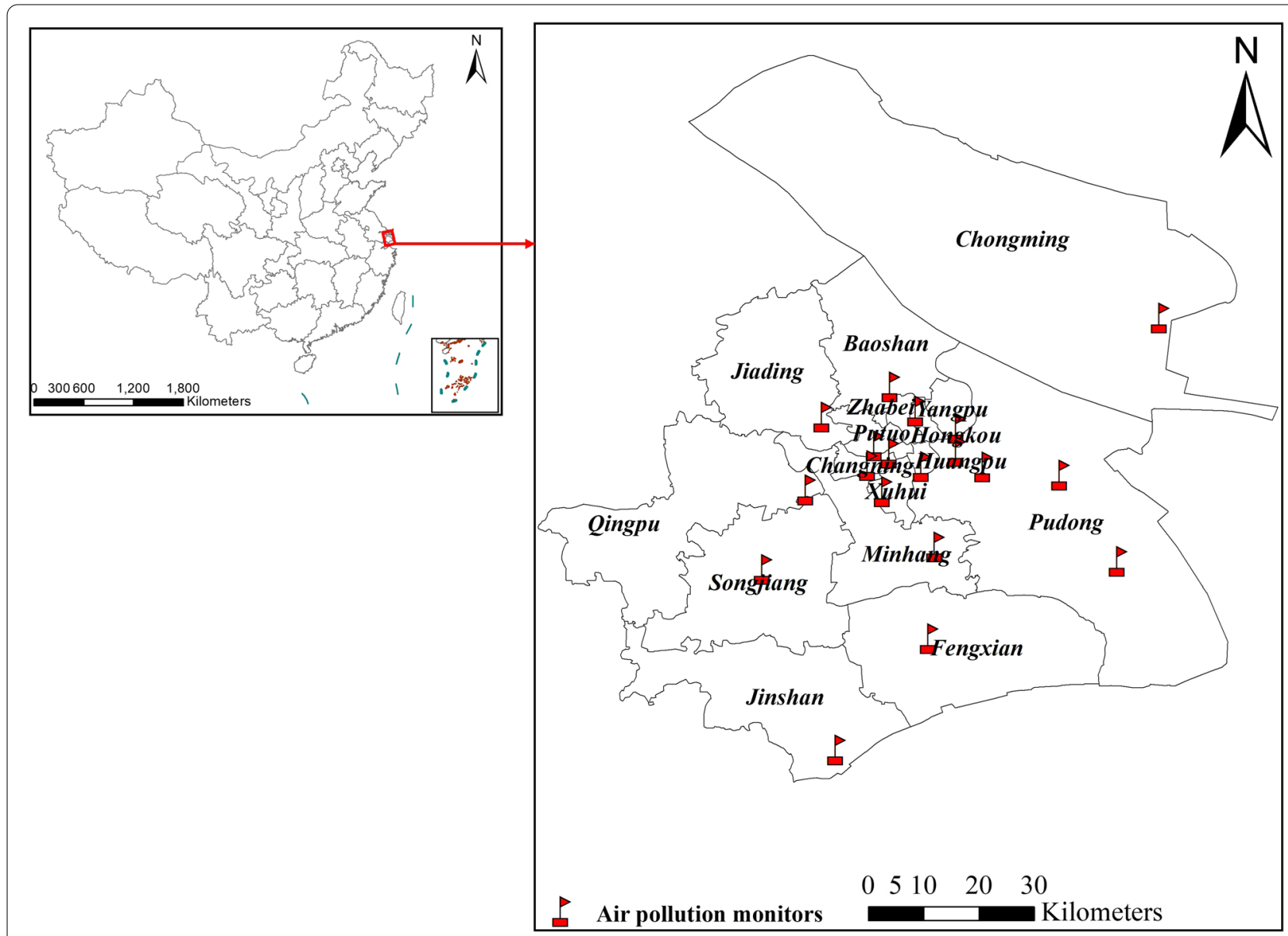

Fig. 1 Locations of air pollution monitors in Shanghai

$$
\log \left(E\left(Y_{t}\right)\right)=\alpha+\beta \times Z_{t}+n s(\text { time }, d f=7 / \text { year })+n s(\text { temperature, } d f=6)+n s(\text { relative humidity, } d f=3)+\text { as.factor }(\text { DOW })+\text { as.factor }(P H)
$$

where $E\left(Y_{t}\right)$ is the estimated daily hospital admissions for respiratory diseases, $Z_{t}$ is the $\mathrm{PM}$ concentration on day $\mathrm{t}, \beta$ is the regression coefficient for $Z_{t}$, and $\alpha$ is the intercept. All results were presented as percentage change with a 95\% confidence interval (CI) for each $10 \mu \mathrm{g} / \mathrm{m}^{3}$ increase of PM. Percentage change was calculated using the following formula [14]:

$$
\text { Percentage Change }=[\exp (\beta \times 10)-1] \times 100
$$

where $\beta$ is the regression coefficient of PM from the GAM model.

Effect modification by individual characteristics was investigated using stratified analyses. The subgroup variables included gender (male and female), age ( $<45,45-, 65-$ and 75 - years), and season (cold: November, December, January, February, March and warm: April, May, June, July, August, September,
October). The subgroup differences were tested using a Z statistic [15]:

$$
Z=\left(\beta_{1}-\beta_{2}\right) / \sqrt{S E_{1}^{2}-S E_{2}^{2}}
$$

where $\beta_{1}$ and $\beta_{2}$ are the effect estimates of the two subgroups, $S E_{1}$ and $S E_{2}$ are their corresponding standard errors.

A cubic spline smoothing method was used to evaluate the exposure-response relationship between $\mathrm{PM}_{2.5}$ and $\mathrm{PM}_{10}$ concentrations and hospital admissions for respiratory diseases.

The attributable fraction (AF) and attributable number (AN) of hospital admissions due to PM exposure were estimated using the following formula based on a previous study [14]:

$$
A F=1-\frac{1}{\exp \left[\beta \times\left(C-C_{0}\right)\right]}
$$


Table 1 Characteristics of hospital admissions for respiratory diseases in Shanghai, China from January 1, 2008 to July 31, 2020

\begin{tabular}{ll}
\hline Characteristics & $\mathbf{n}(\%)$ \\
\hline Admissions of total respiratory diseases & $1,960,361(100.00)$ \\
COPD & $665,541(33.95)$ \\
Asthma & $33,329(1.70)$ \\
Pneumonia & $455,718(23.25)$ \\
Gender & \\
Male & $1,091,645(55.69)$ \\
Female & $868,714(44.31)$ \\
Missing & $2(0.00)$ \\
Age groups, years & \\
$<45$ & $201,952(10.30)$ \\
$45-$ & $410,273(20.93)$ \\
$65-$ & $370,846(18.92)$ \\
$75-$ & $977,289(49.85)$ \\
Missing & $1(0.00)$ \\
Season & \\
Cold & $885,737(45.18)$ \\
Warm & $1,074,624(54.82)$ \\
\hline
\end{tabular}

$$
A N=A F \times N
$$

where $A F$ is the daily attributable fraction, $A N$ is the daily attributable number of hospital admissions due to PM, $N$ is the daily hospital admissions, $\beta$ is the regression coefficient (from the main model above), $C$ is the daily PM concentration, and $C_{0}$ is the reference PM concentration. The reference concentrations were from the air quality guidelines of the WHO: 24-h mean: $15 \mu \mathrm{g} / \mathrm{m}^{3}$ for $\mathrm{PM}_{2.5}$ and $45 \mu \mathrm{g} / \mathrm{m}^{3}$ for $\mathrm{PM}_{10}$. The total attributable number was estimated by summing daily AN.

We also performed three sensitivity analyses to determine the robustness of the results. First, a twopollutant model $\left(\mathrm{PM}_{2.5}, \mathrm{PM}_{10}\right.$ with $\left.\mathrm{O}_{3}, \mathrm{SO}_{2}, \mathrm{NO}_{2}, \mathrm{CO}\right)$ was fitted. Second, we changed the degrees of freedom for the calendar time from 5 to 9 per year. Third, we excluded the data from 2020 due to the coronavirus disease 2019 pandemic.

All data processing and statistical analyses were conducted using R software (version 3.6.1).

\section{Results \\ Hospital admissions for respiratory diseases and meteorological variables}

There were 1,960,361 hospital admissions for total respiratory diseases $(665,541$ for COPD, 455,718 for pneumonia, and 33,329 for asthma) in Shanghai from January 1, 2008 to July 31, 2020 included in our analysis (Table 1). Males accounted for $55.69 \%$ of the patients and $49.85 \%$ of the patients were older than 75 years old.

Analysis of the air pollutants indicated the daily mean concentrations were $43.71 \mu \mathrm{g} / \mathrm{m}^{3}$ for $\mathrm{PM}_{2.5}, 66.12 \mu \mathrm{g} /$ $\mathrm{m}^{3}$ for $\mathrm{PM}_{10}, 45.94 \mu \mathrm{g} / \mathrm{m}^{3}$ for $\mathrm{NO}_{2}, 21.08 \mu \mathrm{g} / \mathrm{m}^{3}$ for $\mathrm{SO}_{2}$, $98.59 \mu \mathrm{g} / \mathrm{m}^{3}$ for $\mathrm{O}_{3}$, and $0.72 \mathrm{mg} / \mathrm{m}^{3}$ for $\mathrm{CO}$ (Table 2). Our analysis of the annual average concentrations indicated decreasing trends for $\mathrm{PM}_{2.5}$ and $\mathrm{PM}_{10}$ from 2013 to 2020 (Table S I).

\section{Correlation between air pollutants and meteorological variables}

We calculated Spearman correlation coefficients to examine the relationships of air pollution variables and meteorological factors (Table S II). The results indicated that daily $\mathrm{PM}_{2.5}$ and $\mathrm{PM}_{10}$ concentrations had positive correlations with $\mathrm{NO}_{2}\left(\mathrm{PM}_{2.5}: \mathrm{r}_{\mathrm{s}}=0.721\right.$, $\left.P<0.001 ; \quad \mathrm{PM}_{10}: \quad \mathrm{r}_{\mathrm{s}}=0.685, \quad \mathrm{P}<0.001\right), \quad \mathrm{SO}_{2} \quad\left(\mathrm{PM}_{2.5}\right.$ : $\left.\mathrm{r}_{\mathrm{s}}=0.729, \quad \mathrm{P}<0.001 ; \quad \mathrm{PM} 10: \mathrm{r}_{\mathrm{s}}=0.655, \quad \mathrm{P}<0.001\right)$, and $\mathrm{CO}\left(\mathrm{PM}_{2.5}: \mathrm{r}_{\mathrm{s}}=0.879, \mathrm{P}<0.001 ; \mathrm{PM}_{10}: \mathrm{r}_{\mathrm{s}}=0.759\right.$,

Table 2 Summary statistics of air pollutants and meteorological variables in Shanghai, China from January 1, 2008 to July 31, 2020

\begin{tabular}{|c|c|c|c|c|c|c|}
\hline Variables & Mean \pm SD & Minimum & P25 & Median & P75 & Maximum \\
\hline \multicolumn{7}{|l|}{ Air pollutants } \\
\hline $\mathrm{PM}_{2.5}, \mu \mathrm{g} / \mathrm{m}^{3 *}$ & $43.71 \pm 31.18$ & 5.00 & 22.00 & 36.00 & 56.00 & 255.00 \\
\hline $\mathrm{PM}_{10}, \mu \mathrm{g} / \mathrm{m}^{3}$ & $66.12 \pm 44.07$ & 6.00 & 37.28 & 54.00 & 82.00 & 599.29 \\
\hline $\mathrm{NO}_{2}, \mu \mathrm{g} / \mathrm{m}^{3}$ & $45.94 \pm 20.31$ & 5.00 & 31.00 & 43.00 & 57.00 & 141.65 \\
\hline $\mathrm{SO}_{2}, \mu \mathrm{g} / \mathrm{m}^{3}$ & $21.08 \pm 17.39$ & 3.00 & 9.00 & 15.00 & 26.83 & 146.78 \\
\hline $\mathrm{O}_{3}, \mu \mathrm{g} / \mathrm{m}^{3 *}$ & $98.59 \pm 41.78$ & 10.00 & 69.00 & 92.00 & 120.00 & 269.00 \\
\hline $\mathrm{CO}, \mathrm{mg} / \mathrm{m}^{3 *}$ & $0.72 \pm 0.26$ & 0.30 & 0.52 & 0.68 & 0.80 & 2.28 \\
\hline \multicolumn{7}{|l|}{ Meteorological factors } \\
\hline Temperature, ${ }^{\circ} \mathrm{C}$ & $17.33 \pm 8.86$ & -6.20 & 9.50 & 18.30 & 24.60 & 35.70 \\
\hline Relative humidity, \% & $71.50 \pm 12.77$ & 23.00 & 63.00 & 72.00 & 81.00 & 100.00 \\
\hline
\end{tabular}

Note: * 2013.1.1-2020.7.31, P25 25th percentile, $P 75$ 75th percentile, SD standard deviation 
$\mathrm{P}<0.001)$. There were inverse correlations of $\mathrm{PM}_{2.5}$ and $\mathrm{PM}_{10}$ concentrations with temperature $\left(\mathrm{PM}_{2.5}\right.$ : $\left.\mathrm{r}_{\mathrm{s}}=-0.311, \mathrm{P}<0.001 ; \mathrm{PM}_{10}: \mathrm{r}_{\mathrm{s}}=-0.229, \mathrm{P}<0.001\right)$ and relative humidity $\left(\mathrm{PM}_{2.5}: \mathrm{r}_{\mathrm{s}}=-0.142, \mathrm{P}<0.001 ; \mathrm{PM}_{10}\right.$ : $\left.\mathrm{r}_{\mathrm{s}}=-0.365, \mathrm{P}<0.001\right)$.
Effect estimates between PM and respiratory diseases

We examined the effects of $\mathrm{PM}_{2.5}$ and $\mathrm{PM}_{10}$ on hospital admissions for respiratory diseases using different lag times (Figs. 2 and 3). Overall, a $10 \mu \mathrm{g} / \mathrm{m}^{3}$ increase of each PM was associated with increased total respiratory
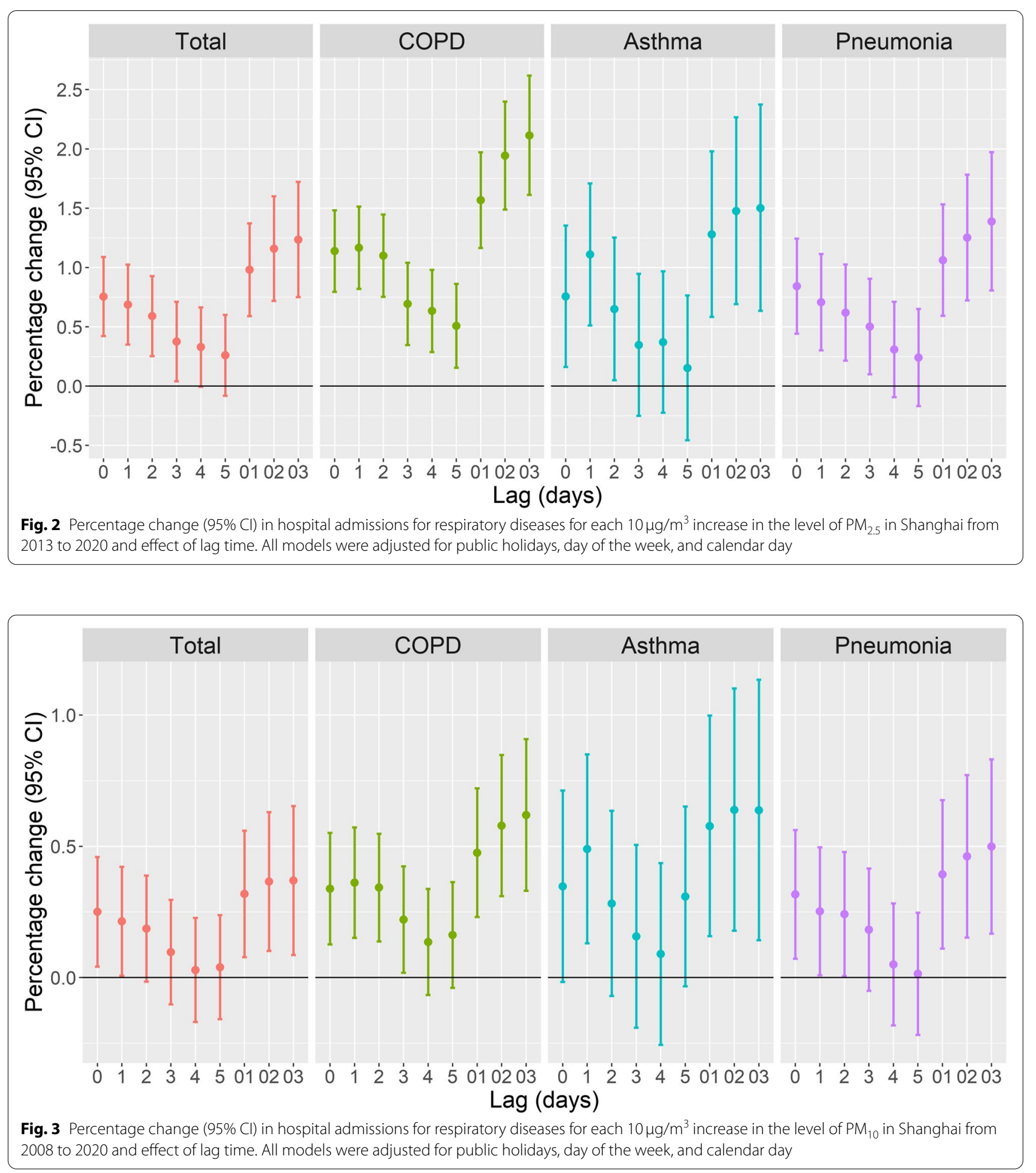
diseases at lag $0\left(\mathrm{PM}_{2.5}: 0.755 \%\right.$; 95\% CI: 0.422, 1.089\%; $\mathrm{PM}_{10}: 0.250 \%$; 95\% CI: 0.042, 0.459\%). These associations decreased as the lag time increased to lag 5 , but were increasingly greater for moving average exposure lags of lag01, lag02, and lag03. Analysis of each causespecific respiratory disease indicated similar trends as total respiratory diseases. The percentage change seemed to be greater for COPD and asthma at lag $1 . \mathrm{PM}_{2.5}$ had a greater effect than $\mathrm{PM}_{10}$ for all lag times.

\section{Stratified analyses by gender, age, and season}

Stratification by gender indicated the associations of $\mathrm{PM}_{2.5}$ and $\mathrm{PM}_{10}$ were similar in males and females (Table 3). Stratification by age indicated the associations of $\mathrm{PM}_{2.5}$ with total respiratory diseases, asthma, and pneumonia were more pronounced in patients more than 45 years old. For patients younger than 45 years, there were no significant associations of PM with total respiratory diseases or with individual diseases, except for $\mathrm{PM}_{2.5}$ and COPD. Stratification by season indicated the associations were more evident during the cold season, and that there were no significant associations of PM with total respiratory diseases or individual diseases during the warm season. We also analyzed these data using 9 different lag times (Figs. S I - Figs. S VI).

\section{Exposure-response relationships}

Exposure-response curves indicated that the percentage change of all types of respiratory diseases increased as PM concentrations increased (Figs. 4 and 5); these relationships were linear at low PM concentrations $\left(0 \sim 100 \mu \mathrm{g} / \mathrm{m}^{3}\right)$, but PM concentrations above $100 \mu \mathrm{g} / \mathrm{m}^{3}$ had less of an effect. Among the cause-specific respiratory diseases, $\mathrm{PM}_{2.5}$ level had a nearly linear association with COPD up to $160 \mu \mathrm{g} / \mathrm{m}^{3}, \mathrm{PM}_{10}$ level had a nearly linear relationship with asthma up to $200 \mu \mathrm{g} / \mathrm{m}^{3}$, and asthma appeared to increase exponentially with $\mathrm{PM}_{2.5}$ level up to $160 \mu \mathrm{g} / \mathrm{m}^{3}$.

\section{Population attributable fraction (PAF)}

We also assessed the excess number of respiratory diseases due to $\mathrm{PM}_{2.5}$ and $\mathrm{PM}_{10}$ levels that exceeded the limits established by the WHO (Table S III - Table S XV). From 2013 to 2020, the overall total excess number of respiratory disease admissions was 21,678 (95\% CI: $21,243,22,112$ ) due to $\mathrm{PM}_{2.5}$ and 5865 (95\% CI: 5587, 6142) due to $\mathrm{PM}_{10}$. There were also trends of decreasing annual admissions for respiratory diseases from 2013 to 2020 .

\section{Sensitivity analyses}

We initially performed a sensitivity analysis by fitting a two-pollutant model (Table S XVI). The results indicated that the associations of $\mathrm{PM}_{2.5}$ and $\mathrm{PM}_{10}$ with total respiratory diseases and individual diseases remained statistically significant after adjusting for other pollutants, although these effect estimates were not significant after adjusting for $\mathrm{NO}_{2}$. Our second sensitivity analysis indicated almost no change of the effect estimates after changing the degrees of freedom for calendar time (Table S XVII). When excluding the data from 2020, the effect estimates were similar to the main analysis (Table S XVIII).

\section{Discussion}

China is one of the most polluted countries in the world due to the rapid industrialization and urbanization [16]. In 2013, China experienced a severe air pollution event in most parts of the country, an event that was of great concern to the government. China's State Council subsequently issued the Air Pollution Prevention and Control Plan in 2013, and strengthening of environmental protections has greatly reduced pollution in China by $\mathrm{PM}_{2.5}$. In response, the annual PM concentrations in Shanghai decreased markedly from 2013 to 2020. In 2019 , the average $\mathrm{PM}_{2.5}$ concentration $\left(35.17 \mu \mathrm{g} / \mathrm{m}^{3}\right)$ was close to the national secondary standard limit of the Chinese National Ambient Air Quality Standard (35 $\mu \mathrm{g} /$ $\left.\mathrm{m}^{3}\right)$. However, the concentrations were still significantly higher than the Air Quality Guidelines 2021 for $\mathrm{PM}_{2.5}$ $\left(5 \mu \mathrm{g} / \mathrm{m}^{3}\right)$. The health risks from exposure to PM should not be ignored.

\section{Main findings and interpretation}

The present ecological study found that short-term exposure to PM was significantly correlated with an increased risk of hospital admissions for total respiratory diseases and cause-specific respiratory diseases. Several previous studies also suggested an association of PM with respiratory diseases. For example, three studies $[8,17$, 18] reported an association between PM and COPD and two other studies reported that short-term and longterm exposure to $\mathrm{PM}_{2.5}$ and $\mathrm{PM}_{10}$ increased the risk of COPD [19, 20]. Three other studies [21-23] examined the influence of daily PM concentrations on the number of asthma-related admissions. Li et al. [24] found a significant reduction of asthma outpatient visits during the 2008 Olympic and Paralympic Games in Beijing, which they attributed to control measures that were implemented to improve air quality. A recent national time-series study in China from 2014 to 2017 showed a short-term positive association between ambient PM concentration and hospital admissions for pneumonia in Chinese adults [25]. 
Table 3 Percentage change with 95\% confidence interval for hospital admissions of respiratory diseases for a $10 \mu \mathrm{g} / \mathrm{m} 3 \mathrm{increase}$ in particulate matter, by gender, age groups, and season

\begin{tabular}{|c|c|c|c|c|}
\hline \multirow[t]{2}{*}{ Respiratory diseases } & \multicolumn{2}{|l|}{$\mathrm{PM}_{2.5}$} & \multicolumn{2}{|l|}{$\mathrm{PM}_{10}$} \\
\hline & Percentage change $(95 \% \mathrm{Cl})$ & $P$ value & Percentage change $(95 \% \mathrm{Cl})$ & $P$ value \\
\hline Total & $0.755(0.422,1.089)$ & & $0.250(0.042,0.459)$ & \\
\hline \multicolumn{5}{|l|}{ Gender } \\
\hline Male & $0.768(0.439,1.098)$ & - & $0.255(0.052,0.457)$ & - \\
\hline Female & $0.740(0.390,1.092)$ & 0.909 & $0.244(0.018,0.470)$ & 0.943 \\
\hline \multicolumn{5}{|l|}{ Age groups, years } \\
\hline$<45$ & $-0.019(-0.418,0.382)$ & - & $0.006(-0.243,0.255)$ & - \\
\hline $45-$ & $0.701(0.349,1.055)$ & 0.008 & $0.338(0.129,0.549)$ & 0.046 \\
\hline $65-$ & $0.865(0.463,1.268)$ & 0.002 & $0.193(-0.071,0.457)$ & 0.312 \\
\hline$>=75$ & $0.919(0.567,1.273)$ & 0.001 & $0.284(0.058,0.510)$ & 0.105 \\
\hline \multicolumn{5}{|l|}{ Season } \\
\hline Cold & $0.652(0.193,1.114)$ & - & $0.296(-0.010,0.603)$ & - \\
\hline Warm & $0.007(-0.711,0.731)$ & 0.803 & $0.182(-0.173,0.539)$ & 0.643 \\
\hline COPD & $1.167(0.820,1.515)$ & & $0.361(0.151,0.572)$ & \\
\hline \multicolumn{5}{|l|}{ Gender } \\
\hline Male & $1.192(0.840,1.544)$ & - & $0.390(0.182,0.599)$ & - \\
\hline Female & $1.126(0.747,1.507)$ & 0.763 & $0.314(0.079,0.550)$ & 0.636 \\
\hline \multicolumn{5}{|l|}{ Age groups, years } \\
\hline$<45$ & $1.762(0.769,2.765)$ & - & $0.607(-0.038,1.257)$ & - \\
\hline $45-$ & $1.027(0.546,1.510)$ & 0.193 & $0.326(0.052,0.601)$ & 0.433 \\
\hline $65-$ & $1.255(0.827,1.685)$ & 0.359 & $0.428(0.174,0.683)$ & 0.614 \\
\hline$>=75$ & $1.157(0.793,1.523)$ & 0.263 & $0.342(0.120,0.565)$ & 0.448 \\
\hline \multicolumn{5}{|l|}{ Season } \\
\hline Cold & $1.170(0.688,1.655)$ & - & $0.387(0.077,0.699)$ & - \\
\hline Warm & $0.336(-0.407,1.084)$ & 0.066 & $0.251(-0.101,0.604)$ & 0.571 \\
\hline Asthma & $1.110(0.513,1.710)$ & & $0.490(0.131,0.850)$ & \\
\hline \multicolumn{5}{|l|}{ Gender } \\
\hline Male & $0.915(0.147,1.690)$ & - & $0.356(-0.112,0.825)$ & - \\
\hline Female & $1.278(0.527,2.034)$ & 0.509 & $0.607(0.164,1.053)$ & 0.452 \\
\hline \multicolumn{5}{|l|}{ Age groups, years } \\
\hline$<45$ & $-1.176(-2.857,0.534)$ & - & $0.098(-0.851,1.056)$ & - \\
\hline $45-$ & $0.978(0.165,1.799)$ & 0.026 & $0.440(-0.019,0.901)$ & 0.527 \\
\hline $65-$ & $1.358(0.348,2.378)$ & 0.012 & $0.360(-0.330,1.055)$ & 0.663 \\
\hline$>=75$ & $2.161(1.112,3.221)$ & 0.001 & $0.935(0.290,1.583)$ & 0.155 \\
\hline \multicolumn{5}{|l|}{ Season } \\
\hline Cold & $1.186(0.445,1.934)$ & - & $0.534(0.058,1.012)$ & - \\
\hline Warm & $-0.271(-1.500,0.974)$ & 0.049 & $-0.040(-0.670,0.594)$ & 0.179 \\
\hline Pneumonia & $0.842(0.442,1.244)$ & & $0.317(0.072,0.562)$ & \\
\hline \multicolumn{5}{|l|}{ Gender } \\
\hline Male & $0.836(0.432,1.243)$ & - & $0.356(0.113,0.602)$ & - \\
\hline Female & $0.850(0.417,1.286)$ & 0.963 & $0.277(0.006,0.549)$ & 0.672 \\
\hline \multicolumn{5}{|l|}{ Age groups, years } \\
\hline$<45$ & $-0.178(-0.832,0.480)$ & & $-0.036(-0.437,0.367)$ & - \\
\hline $45-$ & $0.966(0.482,1.453)$ & 0.006 & $0.477(0.190,0.765)$ & 0.042 \\
\hline $65-$ & $1.129(0.613,1.648)$ & 0.002 & $0.296(-0.048,0.639)$ & 0.219 \\
\hline$>=75$ & $0.894(0.482,1.308)$ & 0.007 & $0.318(0.058,0.580)$ & 0.148 \\
\hline \multicolumn{5}{|l|}{ Season } \\
\hline Cold & $0.945(0.422,1.470)$ & - & $0.547(0.201,0.895)$ & - \\
\hline Warm & $-0.312(-1.129,0.512)$ & 0.012 & $-0.002(-0.410,0.409)$ & 0.045 \\
\hline
\end{tabular}

Note: Particulate matter concentration is lag 0 for total respiratory diseases and pneumonia; lag 1 for asthma and COPD 

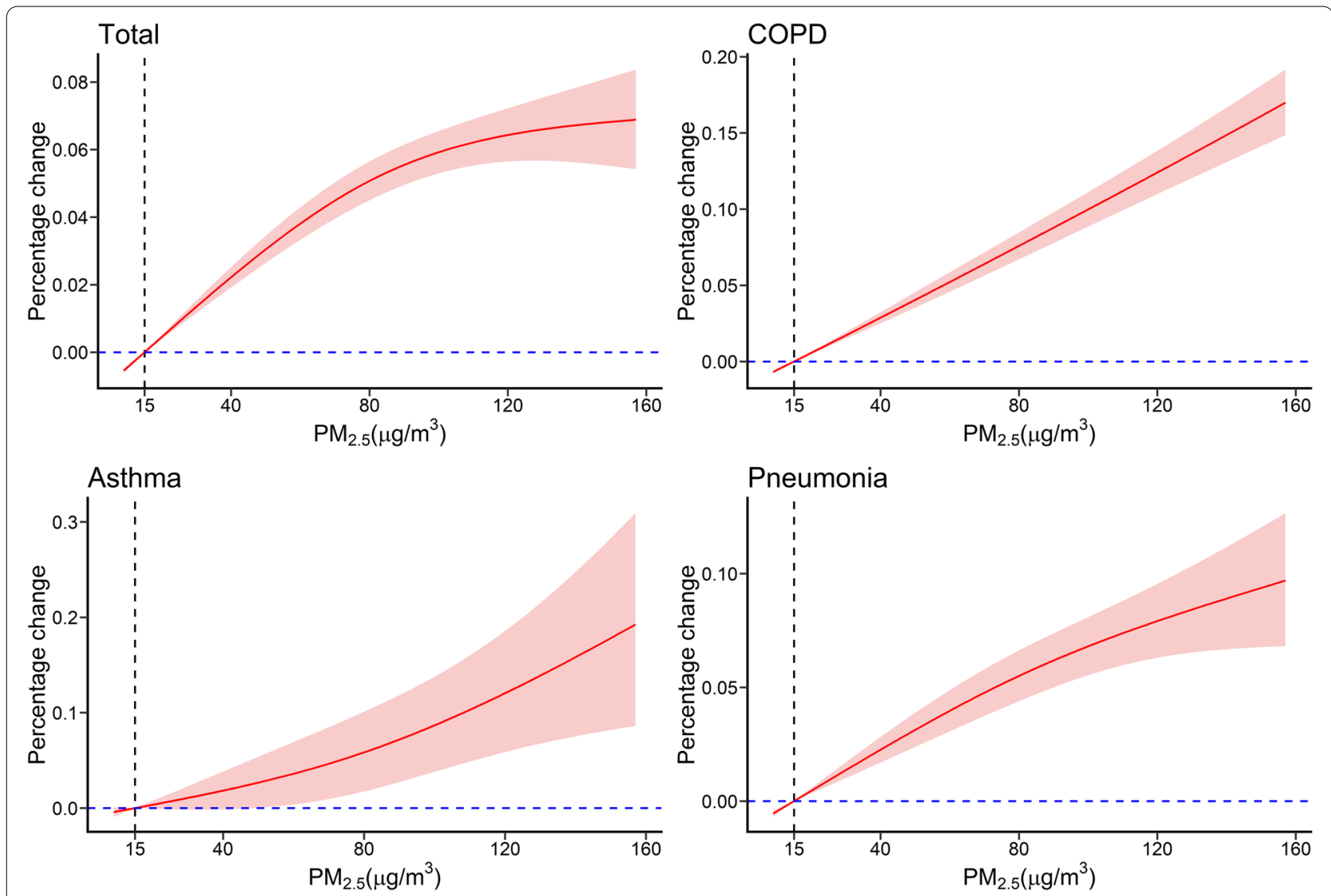

Fig. 4 Relationship of $\mathrm{PM}_{2.5}$ exposure with total respiratory diseases and cause-specific respiratory diseases. The vertical line indicates the air quality standard of the WHO for daily $\mathrm{PM}_{2.5}$ concentration $\left(15 \mu \mathrm{g} / \mathrm{m}^{3}\right)$

In line with previous studies $[25,26]$, we found that $\mathrm{PM}_{2.5}$ had a greater impact on respiratory diseases than $\mathrm{PM}_{10}$ at all lag structures. Compared to $\mathrm{PM}_{10}, \mathrm{PM}_{2.5}$ adsorbs toxic substances and heavy metals more readily due to its larger relative surface area, it remains suspended in the atmosphere for longer periods, and it enters the terminal alveoli and even the bloodstream more easily [25].

Our age-stratified analysis found a significantly greater effect of PM on total respiratory diseases, asthma, and pneumonia in patients aged 45 years or more. The effect was especially strong in those aged 65 years or above, in accordance with previous studies [25-27]. Aged people may be more vulnerable to $\mathrm{PM}_{2.5}$ due to their weaker immune responses [28, 29]. In addition, older people have a higher prevalence of pre-existing respiratory diseases [5].

We found a significant association of PM with respiratory diseases during the cold season, but not during the warm season, in line with previous studies of PM and respiratory diseases $[30,31]$. There are several possible explanations for this finding. First, the $\mathrm{PM}_{2.5}$ levels due to heavy pollution were greater during the cold season than the warm season $\left(55.42 \mu \mathrm{g} / \mathrm{m}^{3}\right.$ vs. $\left.35.41 \mu \mathrm{g} / \mathrm{m}^{3}\right)$. Second, low temperatures prolong the survival of respiratory viruses in the environment [32]. Third, inhalation of cold air can inhibit the mucociliary clearance and thereby promote the spread of viruses in the respiratory tract [33].

Our analysis of exposure-response relationships indicated a linear association between PM and total respiratory diseases at lower concentrations, but a progressively weaker effect of PM on respiratory diseases at concentrations above $100 \mu \mathrm{g} / \mathrm{m}^{3}$. These results are similar to those of a time-series study of 245,442 respiratory visits in Nanjing, China that examined the association of PM with respiratory system diseases [10]. Tian et al. [25] also reported a nonlinear relationship between $\mathrm{PM}_{2.5}$ level and pneumonia, with a weaker effect at higher concentrations. This nonlinear relationship may be because people avoid spending time outside or wear a dust mask when outside when the air is heavily polluted. The exposureresponse curves suggested no discernible thresholds of PM. Exposure to $\mathrm{PM}_{2.5}$ and $\mathrm{PM}_{10}$ even at concentrations below the current regulatory limits is associated with 


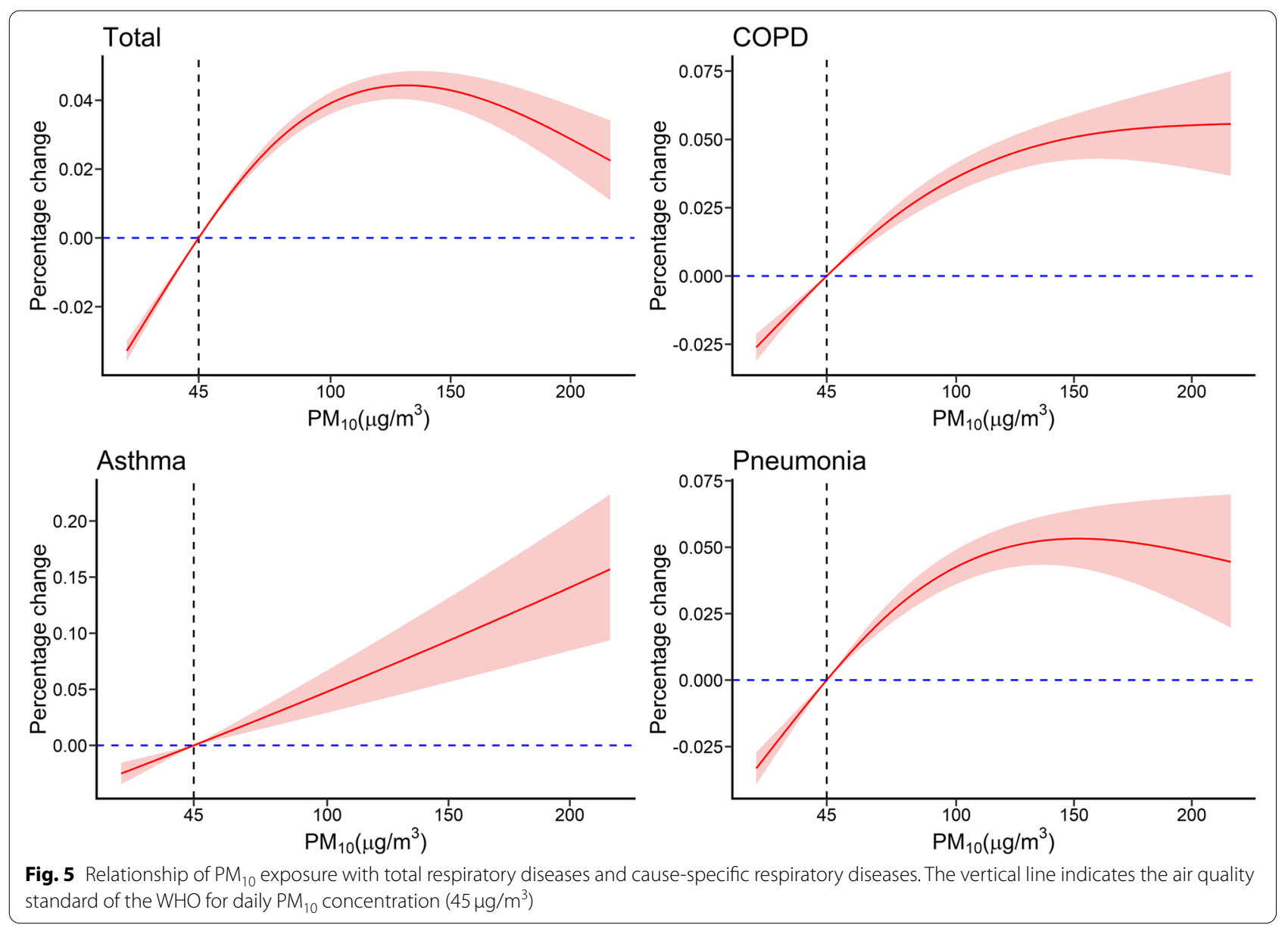

increases in daily admissions, suggesting that tightening the current air quality guidelines of PM for greater public health benefit is necessary.

Our two-pollutant model indicated the associations between PM and respiratory diseases remained positive, but not significant after adjusting for $\mathrm{NO}_{2}$. Previous studies reported similar results. For example, Tian et al. [25] reported no significant association between PM and pneumonia after controlling for $\mathrm{NO}_{2}$. Liu et al. [34] suggested that the effect of PM on respiratory admissions decreased dramatically and was no longer significant after controlling for $\mathrm{NO}_{2}$. Tsai et al. [35] found that the adverse effect of $\mathrm{PM}_{2.5}$ was not statistically significant after adjusting for $\mathrm{NO}_{2}$ or $\mathrm{CO}$. It is possible that a high correlation among pollutants weakened the effect estimation. Therefore, the independent effect of PM on respiratory diseases should be examined.

\section{Potential mechanism}

The potential biological mechanism linking the exposure to PM and hospital admissions for respiratory diseases are not fully understood, but there are several plausible mechanisms. First, exposure to PM may lead to oxidative stress. For example, $\mathrm{PM}_{2.5}$ can easily adsorb organic pollutants, such as polycyclic aromatic hydrocarbons and heavy metals, which promote the production of reactive oxygen species in lung cells, consume antioxidant substances, trigger oxidative stress reactions, and induce lung inflammation [36]. A meta-analysis [37] of epidemiology studies suggested that short-term exposure to $\mathrm{PM}_{2.5}$ was associated with an increased level of malondialdehyde, a biomarker of oxidative stress. Second, $\mathrm{PM}_{2.5}$ induction of a local or systematic inflammatory reaction is the major pathologic basis for the onset and progression of several related diseases [38]. Evidence from a meta-analysis [39] also showed that PM exposure increased the levels of fibrinogen and TNF- $\alpha$.

\section{Limitations}

Compared with previous studies, we used a larger sample size and examined a longer time period, resulting in greater statistical power. However, this study had several limitations. First, our study was a one-city observational study, and multi-city studies are necessary to validate our 
conclusions. Second, due to unavailability of residential location where each patient lived, we used average concentrations of daily air pollutants from fixed environmental monitoring stations as an indicator of exposure. This might result in measurement error, which tends to be nondifferential and underestimate the effect of the PM effects [40]. Previous studies used satellite-derived $\mathrm{PM}_{2.5}$ concentrations based on modeling techniques to represent individual exposure levels and to examine the potential effect on several diseases, including asthma [41] and poor birth outcome [42]. Third, potential confounders, including education level, occupation, socioeconomic status (e.g., family income), and individual behaviors (e.g., smoking status), were not available from the medical insurance system, making stratified analysis impossible. Finally, this study was a time-series ecological investigation of the associations of PM with health outcomes, and cannot make definitive conclusions regarding causality. Our results also could have been affected by the ecological fallacy.

\section{Conclusion}

The main result of this study is that short-term exposure to PM in Shanghai was significantly associated with hospital admissions for total respiratory diseases and cause-specific respiratory diseases - COPD, asthma, and pneumonia. These associations were especially stronger for patients more than 45 years old and during the cold season. PM level had a nearly linear relationship with total respiratory diseases at low concentrations $\left(0 \sim 100 \mu \mathrm{g} / \mathrm{m}^{3}\right)$, but had a weaker as PM concentrations increased. Reducing atmospheric PM concentrations may reduce hospital admissions for respiratory diseases. These findings have important implications for policymakers to take concrete actions to reduce atmospheric PM concentrations. Further studies conducted on nationwide regions are required to validate our results.

\section{Supplementary Information}

The online version contains supplementary material available at https://doi. org/10.1186/s12940-021-00828-6.

Additional file 1: Table SI. The annual average concentrations of PMs in Shanghai. Table S II. Spearman correlation coefficients among air pollution variables and meteorological factors. Table S III. The attributable number of respiratory diseases admissions due to exceeding $\mathrm{PM}_{2.5}$ concentrations. Table S IV. The attributable number of respiratory diseases admissions due to exceeding $\mathrm{PM}_{10}$ concentrations. Table $\mathbf{S} \mathbf{V}$. The attributable number of respiratory diseases admissions due to exceeding $\mathrm{PM}_{2.5}$ concentrations in males. Table S VI. The attributable number of respiratory diseases admissions due to exceeding $\mathrm{PM}_{2.5}$ concentrations in females. Table S VII. The attributable number of respiratory diseases admissions due to exceeding $\mathrm{PM}_{10}$ concentrations in males. Table $\mathbf{S}$ VIII. The attributable number of respiratory diseases admissions due to exceeding $\mathrm{PM}_{10}$ concentrations in females. Table $\mathbf{S}$ III. The attributable number of respiratory diseases admissions due to exceeding PM $_{2.5}$ concentrations in $<45$ years. Table $\mathbf{S ~ I X . ~ T h e ~ a t t r i b u t a b l e ~ n u m b e r ~ o f ~}$ respiratory diseases admissions due to exceeding $\mathrm{PM}_{2.5}$ concentrations in
$45 \sim 64$ years. Table $\mathbf{S} \mathbf{X}$. The attributable number of respiratory diseases admissions due to exceeding $\mathrm{PM}_{2.5}$ concentrations in $65 \sim 74$ years. Table $\mathbf{S} \mathbf{X I}$. The attributable number of respiratory diseases admissions due to exceeding PM $_{2.5}$ concentrations in $\geq 75$ years. Table S XII. The attributable number of respiratory diseases admissions due to exceeding $\mathrm{PM}_{10}$ concentrations in $<45$ years. Table $\mathbf{S}$ XIII. The attributable number of respiratory diseases admissions due to exceeding PM $_{10}$ concentrations in $45 \sim 64$ years. Table S XIV. The attributable number of respiratory diseases admissions due to exceeding PM $_{10}$ concentrations in $65 \sim 74$ years. Table $\mathbf{S ~ X V}$. The attributable number of respiratory diseases admissions due to exceeding $\mathrm{PM}_{10}$ concentrations in $\geq 75$ years. Table S XVI. Percentage change with $95 \%$ confidence interval in hospital admissions for respiratory diseases per $10 \mu \mathrm{g} / \mathrm{m}^{3}$ increase in concentrations of $\mathrm{PM}_{2.5}$ and $\mathrm{PM}_{10}$ using two-pollutant models. Table S XVII. Percentage change with 95\% confidence interval in hospital admissions for respiratory diseases associated with a $10 \mu \mathrm{g} / \mathrm{m}^{3}$ increase in concentrations of $\mathrm{PM}_{2.5}$ and $\mathrm{PM}_{10}$ through changing degrees of freedom for the calendar time. Table $\mathbf{S}$ XVIII. Percentage change with $95 \%$ confidence interval in hospital admissions for respiratory diseases associated with a $10 \mu \mathrm{g} / \mathrm{m} 3$ increase in concentrations of $\mathrm{PM}_{25}$ and $\mathrm{PM}_{10}$ through excluding the data from 2020 due to the coronavirus disease 2019 pandemic. Fig. S I. Percentage change with 95\% confidence interval in hospital admissions for respiratory diseases per $10 \mu \mathrm{g} / \mathrm{m}^{3}$ increase in concentrations of $\mathrm{PM}_{2.5}$ stratified by genders. All the models were adjusted by public holidays, DOW, and calendar day. Fig. S II. Percentage change with 95\% confidence interval in hospital admissions for respiratory diseases per $10 \mu \mathrm{g} / \mathrm{m}^{3}$ increase in concentrations of $\mathrm{PM}_{10}$ stratified by genders. All the models were adjusted with public holidays, DOW, and calendar day. Fig. S III. Percentage change with 95\% confidence interval in hospital admissions for respiratory diseases per $10 \mu \mathrm{g} / \mathrm{m}^{3}$ increase in concentrations of $\mathrm{PM}_{2.5}$ stratified by age groups. All the models were adjusted with public holidays, DOW, and calendar day. Fig. S IV. Percentage change with $95 \%$ confidence interval in hospital admissions for respiratory diseases per $10 \mu \mathrm{g} / \mathrm{m}^{3}$ increase in concentrations of $\mathrm{PM}_{10}$ stratified by age groups. All the models were adjusted with public holidays, DOW, and calendar day. Fig. S V. Percentage change with 95\% confidence interval in hospital admissions for respiratory diseases per $10 \mathrm{\mu g} / \mathrm{m}^{3}$ increase in concentrations of $\mathrm{PM}_{2.5}$ stratified by season. All the models were adjusted with public holidays, DOW, and calendar day. Fig. S VI. Percentage change with 95\% confidence interval in hospital admissions for respiratory diseases per $10 \mathrm{\mu g} / \mathrm{m}^{3}$ increase in concentrations of $\mathrm{PM}_{10}$ stratified by season. All the models were adjusted with public holidays, DOW, and calendar day.

\section{Acknowledgments}

We express our sincere gratitude to all participants.

\section{Authors' contributions}

Wenjia Peng: Conceptualization, Software, Formal analysis, Writing - Original Draft. Hao Li: Conceptualization, Data Curation, Software, formal analysis. Li Peng: Data Curation, Resources. Ying Wang: Conceptualization, Writing Review \& Editing, supervision. Weibing Wang: Conceptualization, Resources, Methodology, Writing - Review \& Editing, Project administration, Funding acquisition. The author(s) read and approved the final manuscript.

\section{Funding}

This work was supported by the Bill \& Melinda Gates Foundation, Seattle, WA (Grant number INV-006277), Shanghai Municipal Health Commission (Grant No. GWV-10.1-XK16), and Science and Technology Commission of Shanghai Municipality (Grant No. 21002411400).

\section{Availability of data and materials}

The data that support the findings of this study are available from the corresponding author upon reasonable request.

\section{Declarations}

Ethics approval and consent to participate

Not applicable. 


\section{Consent for publication}

All authors have approved the manuscript for submission.

\section{Competing interests}

The authors declare that they have no competing interests.

\begin{abstract}
Author details
'Department of Epidemiology, School of Public Health, Fudan University, Shanghai 200032, China. ${ }^{2}$ Department of Epidemiology, Shanghai Key Laboratory of Meteorology and Health, Shanghai 200032, China. ${ }^{3}$ Key Laboratory of Health Technology Assessment, National Health and Family Planning Commission of the People's Republic of China, Fudan University, Shanghai, China. ${ }^{4}$ Department of Social Medicine, School of Public Health, Fudan University, Shanghai 200032, China. ${ }^{5}$ IRDR-ICoE on Risk Interconnectivity and Governance on Weather/Climate Extremes Impact and Public Health, Fudan University, Shanghai 200032, China.
\end{abstract}

Received: 17 Auqust 2021 Accepted: 27 December 2021 Published online: 13 January 2022

\section{References}

1. Lancet T. GBD 2017: a fragile world. Lancet. 2018;392(10159):1683.

2. Li X, Cao X, Guo M, Xie M, Liu X. Trends and risk factors of mortality and disability adjusted life years for chronic respiratory diseases from 1990 to 2017: systematic analysis for the global burden of disease study 2017. BMJ. 2020;368:m234.

3. Yin P, Brauer M, Cohen AJ, Wang H, Li J, Burnett RT, et al. The effect of air pollution on deaths, disease burden, and life expectancy across China and its provinces, 1990-2017: an analysis for the global burden of disease study 2017. Lancet Planetary Health. 2020;4(9):e386-98.

4. Kim KH, Kabir E, Kabir S. A review on the human health impact of airborne particulate matter. Environ Int. 2015;74:136-43.

5. Xu Q, Li X, Wang S, Wang C, Huang F, Gao Q, et al. Fine particulate air pollution and hospital emergency room visits for respiratory disease in urban areas in Beijing, China, in 2013. PLoS One. 2016;11(4):e0153099.

6. Sun Q, Liu C, Chen R, Wang C, Li J, Sun J, et al. Association of fine particulate matter on acute exacerbation of chronic obstructive pulmonary disease in Yancheng, China. Sci Total Environ. 2019;650(Pt 2):1665-70.

7. Zhang $H$, Niu Y, Yao Y, Chen R, Zhou X, Kan H. The impact of ambient air pollution on daily hospital visits for various respiratory diseases and the relevant medical expenditures in Shanghai, China. Int J Environ Res Public Health. 2018:15:3.

8. Zhang Z, Chai P, Wang J, Ye Z, Shen P, Lu H, et al. Association of particulate matter air pollution and hospital visits for respiratory diseases: a timeseries study from China. Environ Sci Pollut Res Int. 2019;26(12):12280-7.

9. Wang $Y, Z u Y$, , Huang L, Zhang H, Wang C, Hu J. Associations between daily outpatient visits for respiratory diseases and ambient fine particulate matter and ozone levels in Shanghai, China. Environ Pollut. 2018:240:754-63.

10. Wang C, Feng $L$, Chen $K$. The impact of ambient particulate matter on hospital outpatient visits for respiratory and circulatory system disease in an urban Chinese population. Sci Total Environ. 2019;666:672-9.

11. Hastie T, Tibshirani R. Generalized additive models for medical research. Stat Methods Med Res. 1995;4(3):187-96.

12. Chen C, Liu C, Chen R, Wang W, Li W, Kan H, et al. Ambient air pollution and daily hospital admissions for mental disorders in Shanghai, China. Sci Total Environ. 2018;613-614:324-30.

13. Gao Q, Xu Q, Guo X, Fan H, Zhu H. Particulate matter air pollution associated with hospital admissions for mental disorders: a time-series study in Beijing, China. Eur Psychiatry. 2017;44:68-75.

14. Wang $X, Y u$ C, Zhang Y, Shi F, Meng R, Yu Y. Attributable risk and economic cost of cardiovascular hospital admissions due to ambient particulate matter in Wuhan, China. Int J Environ Res Public Health. 2020;17:15.

15. Altman DG, Bland JM. Interaction revisited: the difference between two estimates. BMJ. 2003;326(7382):219.

16. Rohde RA, Muller RA. Air pollution in China: mapping of concentrations and sources. PLoS One. 2015;10(8):e0135749.

17. Wang $C, X u$ J, Yang L, Xu Y, Zhang X, Bai C, et al. Prevalence and risk factors of chronic obstructive pulmonary disease in China (the China pulmonary health $[\mathrm{CPH}]$ study): a national cross-sectional study. Lancet. 2018:391(10131):1706-17.

18. Zhang Y, Wang Z, Xu J, Liu Y, Zhou B, Zhang N, et al. Association between consecutive ambient air pollution and chronic obstructive pulmonary disease hospitalization: time series study during 2015-2017 in Chengdu China. Annu Int Conf IEEE Eng Med Biol Soc. 2020:2020:5378-81.

19. Pun VC, Kazemiparkouhi F, Manjourides J, Suh HH. Long-term PM2.5 exposure and respiratory, Cancer, and cardiovascular mortality in older US adults. Am J Epidemiol. 2017;186(8):961-9.

20. Wang K, Hao Y, Au W, Christiani DC, Xia ZL. A systematic review and Meta-analysis on short-term particulate matter exposure and chronic obstructive pulmonary disease hospitalizations in China. J Occup Environ Med. 2019:61(4):e112-24

21. AlBalawi SM, Namdeo A, Hodgson S, Pless-Mulloli T, McNally RJQ. Shortterm effects of air pollution on daily asthma-related emergency department visits in an industrial city. J Public Health (Oxf). 2021;43(1):e45-e53.

22. Lu P, Zhang Y, Lin J, Xia G, Zhang W, Knibbs LD, et al. Multi-city study on air pollution and hospital outpatient visits for asthma in China. Environ Pollut. 2020:257:113638.

23. Zheng XY, Ding H, Jiang LN, Chen SW, Zheng JP, Qiu M, et al. Association between air pollutants and asthma emergency room visits and hospital admissions in time series studies: a systematic review and Meta-analysis. PLoS One. 2015;10(9):e0138146.

24. Li Y, Wang W, Kan H, Xu X, Chen B. Air quality and outpatient visits for asthma in adults during the 2008 summer Olympic games in Beijing. Sci Total Environ. 2010:408(5):1226-7.

25. Tian Y, Liu H, Wu Y, Si Y, Li M, Wu Y, et al. Ambient particulate matter pollution and adult hospital admissions for pneumonia in urban China: a national time series analysis for 2014 through 2017. PLoS Med. 2019:16(12):e1003010.

26. Yao C, Wang Y, Williams C, Xu C, Kartsonaki C, Lin Y, et al. The association between high particulate matter pollution and daily cause-specific hospital admissions: a time-series study in Yichang, China. Environ Sci Pollut Res Int. 2020;27(5):5240-50.

27. Tao Y, Mi S, Zhou S, Wang S, Xie X. Air pollution and hospital admissions for respiratory diseases in Lanzhou, China. Environ Pollut. 2014;185:196-201.

28. Kan H, London SJ, Chen G, Zhang Y, Song G, Zhao N, et al. Season, sex, age and education as modifiers of the effects of outdoor air pollution on daily mortality in Shanghai, China: the public health and air pollution in Asia (PAPA) study. Environ Health Perspect. 2008;116(9):1183-8.

29. Tong L, Li K, Zhou Q. Season, sex and age as modifiers in the association of psychosis morbidity with air pollutants: a rising problem in a Chinese metropolis. Sci Total Environ. 2016;541:928-33.

30. Peng L, Xiao S, Gao W, Zhou Y, Zhou J, Yang D, et al. Short-term associations between size-fractionated particulate air pollution and COPD mortality in Shanghai, China. Environ Pollut. 2020;257:113483.

31. Wang X, Guo Y, Li G, Zhang Y, Westerdahl D, Jin X, et al. Spatiotemporal analysis for the effect of ambient particulate matter on cause-specific respiratory mortality in Beijing, China. Environ Sci Pollut Res Int. 2016;23(11):10946-56.

32. Shaw Stewart PD. Seasonality and selective trends in viral acute respiratory tract infections. Med Hypotheses. 2016;86:104-19.

33. Lowen AC, Steel J. Roles of humidity and temperature in shaping influenza seasonality. J Virol. 2014;88(14):7692-5.

34. Liu H, Tian Y, Xiang X, Juan J, Song J, Cao Y, et al. Ambient particulate matter concentrations and hospital admissions in 26 of China's largest cities: a case-crossover study. Epidemiology. 2018;29(5):649-57.

35. Tsai SS, Chang CC, Liou SH, Yang CY. The effects of fine particulate air pollution on daily mortality: a case-crossover study in a subtropical city, Taipei, Taiwan. Int J Environ Res Public Health. 2014;11(5):5081-93.

36. Gurgueira SA, Lawrence J, Coull B, Murthy GG, Gonzalez-Flecha B. Rapid increases in the steady-state concentration of reactive oxygen species in the lungs and heart after particulate air pollution inhalation. Environ Health Perspect. 2002;110(8):749-55.

37. Li Z, Liu Q, Xu Z, Guo X, Wu S. Association between short-term exposure to ambient particulate air pollution and biomarkers of oxidative stress: a meta-analysis. Environ Res. 2020;191:110105.

38. Valavanidis A, Vlachogianni T, Fiotakis K, Loridas S. Pulmonary oxidative stress, inflammation and cancer: respirable particulate matter, fibrous 
dusts and ozone as major causes of lung carcinogenesis through reactive oxygen species mechanisms. Int J Environ Res Public Health. 2013;10(9):3886-907.

39. Tang H, Cheng Z, Li N, Mao S, Ma R, He H, et al. The short- and long-term associations of particulate matter with inflammation and blood coagulation markers: a meta-analysis. Environ Pollut. 2020;267:115630.

40. Goldman GT, Mulholland JA, Russell AG, Strickland MJ, Klein M, Waller LA, et al. Impact of exposure measurement error in air pollution epidemiology: effect of error type in time-series studies. Environ Health. 2011:10:61.

41. Chang HH, Pan A, Lary DJ, Waller LA, Zhang L, Brackin BT, et al. Time-series analysis of satellite-derived fine particulate matter pollution and asthma morbidity in Jackson, MS. Environ Monit Assess. 2019;191(Suppl 2):280.

42. Kloog I, Melly SJ, Ridgway WL, Coull BA, Schwartz J. Using new satellite based exposure methods to study the association between pregnancy PM2.5 exposure, premature birth and birth weight in Massachusetts. Environ Health. 2012;11:40.

\section{Publisher's Note}

Springer Nature remains neutral with regard to jurisdictional claims in published maps and institutional affiliations.

- fast, convenient online submission

- thorough peer review by experienced researchers in your field

- rapid publication on acceptance

- support for research data, including large and complex data types

- gold Open Access which fosters wider collaboration and increased citations

- maximum visibility for your research: over $100 \mathrm{M}$ website views per year

At BMC, research is always in progress.

Learn more biomedcentral.com/submissions 